\title{
Experimental Comparisons of Leading Display and RSVP Display of Chinese Dynamic Text in Searching Tasks
}

\author{
Songzhen Tong, Pilsung Choe, Pei Shi, Lin Yang \\ Department of Industrial Engineering, Tsinghua University, Beijing, 100084, P.R. China
}

\begin{abstract}
Objective: This study investigates user performance and user perceptions of dynamic Chinese text displays (Leading display and RSVP display) when users search for target information. Background: Today, information searching with dynamic displays is widely used in TV programs, on Internet advertisements, for traffic information systems, and more. Method: A human factors experiment was conducted to compare both displays. Eighteen subjects participated in evaluating two simulated interfaces for the leading display and the RSVP display. Results: The results show that the leading display was better in terms of search time and certain subjective measurements (Easiness, frustration, anxiety). The latter results are consistent with the conclusions of other research efforts showing that dynamic displays are more effective and efficient when reading information. Conclusion: The leading display is more useful for Chinese users in terms of both information searching and information reading. Application: This study helps design dynamic displays written in Chinese texts.
\end{abstract}

Keywords: Dynamic display, RSVP display, Leading display, Chinese text, Information search

\section{Introduction}

Dynamic displays are often used to show text information for limited time frames and with limited display spaces (Kang and Muter, 1989). Today, dynamic displays are widely used in TV programs, on Internet advertisements, for traffic information systems, and more. With the usage increase of dynamic displays, there has been considerable research on the effects of dynamic displays. These researches have mainly focused on the effects of screen types, color displays, moving speed, line length, etc. (Sun et al., 1985; Shneiderman, 1998; Dyson and Haselgrove 20011; Laarni, 2002; Wang et al., 2002; Wang et al., 2003).
Another research interest in dynamic displays is the comparisons of displaying methods classified as the leading display and the RSVP (Rapid Serial Visual Presentation) display (Masson, 1983; Juola et al., 1995; Wang and Chen, 2003; Wang et al., 2003). In the leading display, a string of text moves from right to left sequentially along a single line within a small window (Chen and Tsoi, 1988). In the RSVP display, text is presented at a fixed location on the screen where the computer successively presents the text segment of one word or a few words at a time. Lin and Shieh (2006) showed there is different user performance and satisfaction when reading the information using the leading display and using the RSVP display. The RSVP can reduce the cognitive load, but it still brings users certain

Corresponding Author: Pilsung Choe. Department of Industrial Engineering, Tsinghua University, Beijing 100084, P.R. China.

Mobile: +86-10-62796593, E-mail: pschoe@gmail.com, pchoe@tsinghua.edu.cn

Copyright@2013 by Ergonomics Society of Korea(pISSN:1229-1684 eISSN:2093-8462). All right reserved.

(c) This is an open-access article distributed under the terms of the Creative Commons Attribution Non-Commercial License(http://creativecommons.org/licenses/by-nc/3.0/), which permits unrestricted non-commercial use, distribution, and reproduction in any medium, provided the original work is properly cited. http://www.esk.or.kr 
time pressures because totally new information is displayed after a predetermined time (Juola et al., 1982; Masson, 1983).

However, most of the earlier studies focused on the effect on reading information through dynamic displays. Sometimes, people just need to search for target information provided by the dynamic displays without reading all the information in the displays while doing other work. People might also glance at the information they are interested in, such as weather information and stock information displayed at the bottom of the TV screen while watching a TV show.

Information searching and reading are both information processing tasks. However, information searching needs a less cognitive process because it is mainly about a visual detection of a target word or a symbol, and information reading needs more mental workload because of the feature of semantics, syntactic, and pragmatics of a language or a symbol. In this regard, information searching and information reading could present different conditions for designing dynamic displays.

Further, Chinese characters are ideograms. Chinese has a different writing orientation, character complexity, word spacing, etc. from western languages, especially English (Tang et al., 1997; Goonetilleke et al., 2002; Yen, 2011). So, other factors can be involved when designing dynamic displays for searching Chinese texts. This study investigates and compares the effects of two dynamic displays (Leading display and RSVP display) when users search for information displayed in Chinese.

\section{Method}

A human factor experiment was conducted at the Usability Laboratory of Tsinghua University in April 2012 to learn these differences in terms of user performance and user perceptions of the two displays. A pre-test was first conducted with 3 participants to find any potential issue that could arise in the experiment. After improving the experimental condition, the main experiment was conducted as follows.

\subsection{Subjects}

Eighteen students at Tsinghua University participated in the experiment, and all were native Chinese speakers. Out of the group, 8 were females and 10 were males, and their average age was 23 . None of them had vision problems that would affect the experiment.

\subsection{Apparatus}

The interfaces for the leading display and the RSVP display used in the experiment were developed using C\# on a Pentium computer in the Microsoft Windows 7 environment. A 14.1-inch monitor was used. The resolution of the screen was $1,280 \times 800$ pixels. As shown in Figure 1, four lines at maximum were presented at the bottom of the screen for each interface, and six stock names and their prices on average were displayed at each line, keeping their spaces equal. The characters were written in 'Song font' in black in 24-point font size. The presented speed for the two

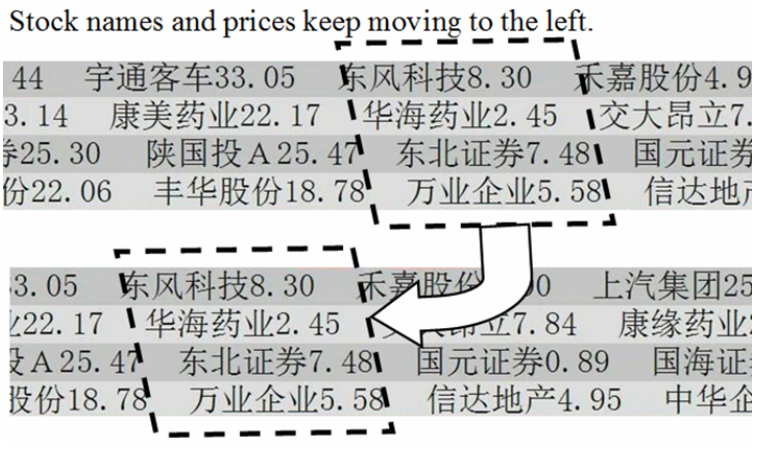

(a) The leading display

Seconds later, totally new stock names and prices are displayed.

\begin{tabular}{|c|c|c|c|}
\hline 佛山照明9. 61 & 格力电器 1.60 & 德豪润达27. 26 & \\
\hline 兴化股份8.57 & 湘潭电化4. 46 & 路翔股份 28.69 & \\
\hline 江集团8. 75 & 世联地产 4.88 & 南国置业16.28 & \\
\hline 利地产 2.51 & 浙江广厦 5.35 & 中江地产 16.79 & \\
\hline 8.73 & 交运股份4.99 & 车16.85 & \\
\hline 守 1.59 & 国农科技8. 53 & 海王生物 16.83 & \\
\hline 8.39 & 开能环保3. 25 & 新疆天业18. 16 & \\
\hline 份 1.99 & 北辰实业 2.99 & 世纪星源13.97 & \\
\hline
\end{tabular}

(b) The RSVP display

Figure 1. Example of displays providing Chinese stock information 
interfaces was set at 205 CPM (Characters per minute) using the recommendation from the previous study (Lin and Shieh, 2006). A total of 408 stocks written in Chinese were chosen from the Sina website (finance.sina.com.cn/ stock/). The number of characters for the stock names was limited to four to minimize errors due to a different length of stock names.

As shown in Figure 2, the screen also showed car pictures that the subjects were asked to appreciate as a primary task during the experiment. The clearance between a subject's eyes and the computer monitor was set at $55 \mathrm{~cm}$. The performance of the subject was observed and the searching time was recorded.

When the leading display was tested, the four-line stock information moved continuously from right to the left on the screen until the last stock disappeared to the left (Figure 1(a)). The exposure time per window for a stock item was 14 seconds for 205 CPM. When the RSVP display was tested, the four-line stock information was discretely presented (i.e. after the four-line stock information, another group of new twenty-four stocks showed up on the screen) (Figure 1(b)). The exposure time per window for a stock item also was 14 seconds at 205 CPM. Each display took about 3 minutes and 40 seconds to present all 408 stocks.

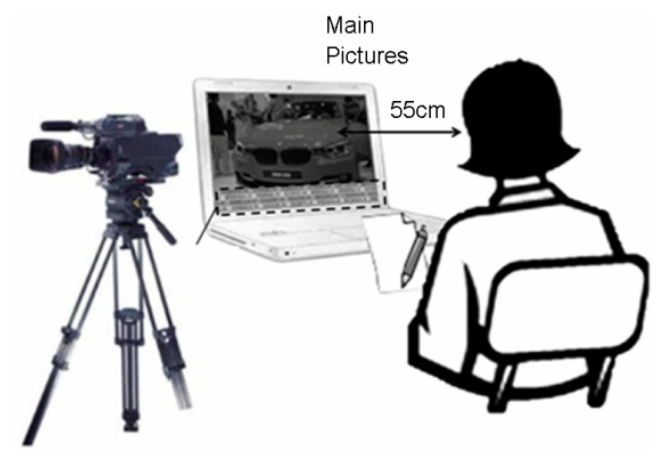

Figure 2. The experiment layout

\subsection{Experiment design and variables}

A within-subject design with one independent variable was used for comparisons, which made the experiment more efficient with a small size of subjects. The independent variable in the experiment was the type of the dynamic display. It had two levels-the leading display and the RSVP display. Two dependent variables-searching time and error rate-were used to measure user performance. Searching time is the interval between the time when the target stock appears and when the subject locates the target stock. The time when the subject begins to write down the stock price was recorded to calculate the searching time. Error rate was the ratio of errors when searching for target stocks. An error meant that the subject failed to locate the target stock before it moved out of the screen.

\subsection{Procedure}

Before the experiment, the subjects were told about the experimental procedure and about the two display interfaces. Each subject was asked to memorize five target stocks randomly chosen from 408 stocks included in the interfaces. The subject was then asked to search for the five target stocks from memory using each display interface. The searching time and errors made by the subject were recorded. The information in each dynamic display was continuously presented until the subject finished the task. After finishing a task searching for 5 target stocks using one interface, the other interface was tested using the same procedure. Nine subjects tested the leading display first, and the other nine subjects tested the RSVP display first.

After the experiment, each subject was asked to fill in a questionnaire. Based on the previous studies (Hornbæk, 2006; Davis, 1989; Riccio et al., 2011; Yamada, 1998; DiDomenico and Nussbaum, 2011), the questionnaire with four questions was developed to measure subject perceptions of the two dynamic displays. These four questions were asked about subject perceptions for ease of use, anxiety, frustration, and concentration. A 5-point Likert scale was used to measure each item ( 1 for absolutely disagree to 5 for absolutely agree).

\section{Results}

\subsection{User performance evaluation}

Paired t-Tests were conducted to examine whether there were significant differences in user performance between the two dynamic displays. As shown in Table 1, the searching times using the leading display and the RSVP display were 
significantly different $(p=0.006)$. The mean searching time for the leading display was significantly shorter than that for the RSVP display. This result revealed that Chinese users quickly found target information when using the leading display. However, there was no significant difference in the error rate $(p=0.834)$ as shown in Table 2 .

Table 1. T-Test result for searching time

\begin{tabular}{c|c|c|c|c|c}
\hline Display & Mean & Variance & df & T-stat & $p$-value \\
\hline Leading & 4.98 & 1.974 & 17 & -3.100 & $0.006^{* *}$ \\
\hline RSVP & 6.72 & 3.960 & & & \\
\hline \multicolumn{5}{c}{$* *$ significant at $\alpha=0.05$}
\end{tabular}

Table 2. T-Test result for error rate

\begin{tabular}{c|c|c|c|c|c}
\hline Display & Mean & Variance & $\mathrm{df}$ & T-stat & $p$-value \\
\hline Leading & 1.00 & 0.706 & 17 & 0.212 & 0.834 \\
\hline RSVP & 0.94 & 1.232 & & & \\
\hline
\end{tabular}

Paired $t$-Tests were also conducted to examine if there were significant differences in user perception between the two displays. As shown in Table 3, subjects preferred the leading display for all items except for 'Concentration'. That is, subjects felt more easiness, less frustration, and less anxiety when searching for the target items using the leading display. The mean score for 'Concentration' of the leading display was lower, which meant the mental workload for the information search using the leading display was lighter. Yet the difference was not significant at $\alpha=0.05$ $(p=0.1107)$. Overall, the subjects were more satisfied with

Table 3. T-Test results for user perceptions

\begin{tabular}{c|c|c|c|c|c|c}
\hline Measurement & Display & Mean & Variance & df & $t$ & $p$-value \\
\hline \multirow{2}{*}{ Ease of use } & Leading & 3.82 & 0.779 & 17 & 3.364 & $0.004^{* *}$ \\
\cline { 2 - 8 } & RSVP & 2.76 & 0.816 & & & \\
\hline \multirow{3}{*}{ Anxiety } & Leading & 2.59 & 1.632 & 17 & -3.105 & $0.007^{* *}$ \\
\cline { 2 - 8 } & RSVP & 3.82 & 0.779 & & & \\
\hline \multirow{2}{*}{ Frustration } & Leading & 2.29 & 1.096 & 17 & -2.194 & $0.043^{* *}$ \\
\cline { 2 - 8 } & RSVP & 3.06 & 0.809 & & & \\
\hline \multirow{2}{*}{ Concentration } & Leading & 3.41 & 1.632 & 17 & -1.689 & 0.111 \\
\cline { 2 - 8 } & RSVP & 4.12 & 0.735 & & & \multicolumn{7}{c}{$* *$ significant at $\alpha=0.05$}
\end{tabular}

the leading display than with the RSVP display for all perceptions, which was consistent with the result of the question asking for a preference between the two displays. Among the 18 subjects, only 4 preferred the RSVP display for the searching task.

\section{Conclusions and Discussion}

An experimental study was conducted to compare the two dynamic displays (Leading display and RSVP display) in terms of user performance and perception of the Chinese subjects in their searches for the stock information written in Chinese. The leading display was better than the RSVP display in terms of searching time, while there was no significant difference in the error rate between the two displays. In terms of user perception, Chinese users indicated that the leading display was better than the RSVP for all measurements (Ease of use, frustration, anxiety, and concentration) for the information search. However, there was no significant difference in concentration. Because the number of subjects in this experiment was relatively small and the score difference for the concentration was marginally significant at $\alpha=0.1$, more study is needed here.

Overall, the leading display showed better user performance and higher satisfaction than did the RSVP display in an information search by Chinese users. Many subjects made a random search in the RSVP display, while they were forced to read the displayed information sequentially in the leading display. The latter searching strategy with the RSVP display gave the subjects greater mental workload and anxiety resulting in less satisfaction and poorer performance when locating the target information. In addition, the way the leading display showed the information matches the way Chinese read information left to right. Even though Chinese read right to left in the past, most Chinese readers already had become used to reading left to right in the new reading system in China.

The fact that the leading display was better than the RSVP display in the information search in Chinese texts is in accordance with the results from the previous research about information reading of Chinese texts (Lin, 2005; Lin and Shieh, 2006; Yen, 2011). While accuracy did not present any significant difference when searching for information 
in this study, other research has shown significant difference in the accuracy of reading information for the two displays in Chinese texts (Lin and Shieh, 2006; Laarni, 2002). Laarni (2002) ascribed the poorer accuracy of the RSVP display to a lack of context for the reading. That is, users of the RSVP display have to integrate the presented words to the sentence to understand the full information when reading. This latter interpretation might explain why there was no significance for the error rate in this study because understanding context is not necessary in an information search. However, because of the limitation of a small sample size in this study, we need further research to draw a firm conclusion for this aspect.

Although much research has shown the superiority of the leading display over the RSVP display in terms of user performance and satisfaction, other research has tried to find a potential use of the RSVP display for reading information as an alternative to the leading display. For example, Chen and Chien (2007) suggest a single-line RSVP display for information reading in public places. Likewise, we might consider the RSVP display for information search in certain specific cases, such in public places or for providing the secondary information, so people who might not be interested in the information are not annoyed as much.

This research also has certain limitations in terms of generalization. The amount of information in the display might affect the results because the leading display has more advantages from long information sentences. In this regard, we need to study the relationship between the display type and the amount of information specified by the number of words, the number of lines further. In addition, this study only used four Chinese characters of stock names and numbers as target information for searching. Other features of targets, such as long words and pictorial symbols could be an additional interesting issue for a further study. The effect of screen size, information layout, and information location also needs to further research. Further studies will be extended to English information searching because we only investigated Chinese texts on these displays in the research. As aforementioned, written English is different from written Chinese in terms of writting orientation, characters' complexity, word spacing, etc. (Tang et al., 1997), which could greatly affect searching performance (Sun et al., 1985) when using dynamic displays. In this light, a further study for English information searching and comparisons with Chinese information searching are expected to provide extensive display design guidelines for different features of languages as well as Chinese and English. Further, we need to carefully interpret the results obtained in this study because the task used in the experiment is simple, and the sample size is relatively small. Error rate for example, the result did not show significant difference between two displays. But, we assume that it is because subjects made very few mistakes during the experiment because of the simplicity of the searching task.

Despite these limitations, this research does add to the superiority of the leading display for information searching and the conclusions regarding information reading generally accepted from the previous research.

\section{References}

Chen, C. and Chien, Y., Effects of RSVP display design on visual performance in accomplishing dual tasks with small screens, International Journal of Design, 1(1), 27-35, 2007.

Chen, H. and Tsoi, K., Factors an affecting the readability of moving text on a computer display, Human Factors: The Journal of the Human Factors and Ergonomics Society, 30(1), 25-33, 1988.

Davis, F.D., Perceived usefulness, perceived ease of use, and user acceptance of information technology, MIS Quarterly, 13(3), 319-340, 1989.

DiDomenico, A. and Nussbaum, M.A., Effects of different physical workload parameters on mental workload and performance, International Journal of Industrial Ergonomics, 41(3), 255-260, 2011.

Dyson, M.C. and Haselgrove, M., The influence of reading speed and line length on the effectiveness of reading from screen, International Journal of Human-Computer Studies, 54(4), 585-612, 2001.

Goonetilleke, R.S., Lau, W.C. and Shih, H.M., Visual search strategies and eye movements when searching Chinese character screens, International Journal of Human-Computer Studies, 57(6), 447-468, 2002.

Hornbæk, K., Current practice in measuring usability: challenges to usability studies and research, International Journal of Human-Computer Studies, 64(2), 79-102, 2006.

Juola, J.F., Tiritoglu, A. and Pleunis, J., Reading text presented on a small display, Applied Ergonomics, 26(3), 227-229, 1995.

Juola, J.F., Ward, N.J. and McNamara, T., Visual search and reading of rapid serial presentation of letter strings, words, and text, Journal of Experimental Psychology: General, 111(2), 208-227, 1982.

Kang, T.J. and Muter, P., Reading dynamically displayed text, Behavior and Information Technology, 8(1), 33-42, 1989.

Laarni, J., "Searching for Optimal Methods of Presenting Dynamic Text on Different Types of Screens", Proceedings of the second Nordic 
conference on Human-computer interaction, (pp. 19-23), New York. 2002.

Lin, Y. and Shieh, K., Reading a dynamic presentation of Chinese text on a single-line display, Displays, 27(4-5), 145-152, 2006.

Lin, Y., Ergonomic design on reading dynamic Chinese text from singleline displays. Thesis $(P h D)$. National Taiwan Technology University, 2005.

Masson, M.E.J., Conceptual processing of text during skimming and rapid sequential reading, Memory \& Cognition, 11(3), 262-274, 1983.

Riccio, A., et al. Workload measurement in a communication application operated through a P300-based brain-computer interface, Journal of Neural Engineering, 8(2), 1-6, 2011.

Shneiderman, B., Designing the User Interface: Strategies for Effective Human-Computer Interaction. In Reading ( $3^{\text {rd }}$ ed.). Reading, Addison Wesley. 1998.

Sun, F., Morita, M. and Stark, L.W., Comparative patterns of reading eye movement in Chinese and English, Attention, Perception, \& Psychophysics, 37(6), 502-506, 1985.

Tang, C., Yeung, L.A. and Chen, H., "The effective visual field in Chinese Reading", Cognitive processing of Chinese and related Asian languages, (pp.267-286), Hong Kong, 1997.

Wang, A. and Chen, C., Effects of screen type, Chinese typography, text /background color combination, speed, and jump length for VDT leading display on users' reading performance, International Journal of Industrial Ergonomics, 31(4), 249-261, 2003.

Wang, A., Chen, C. and Chen, M., Effect of VDT leading display design of dynamic information on users' visual performance and visual fatigue, Journal of the Chinese Institute of Industrial Engineers, 19(2), 69-78, 2002.

Wang, A., Fang, J. and Chen, C., Effects of VDT leading-display design on visual performance of users in handing static and dynamic display information dual-tasks, International Journal of Industrial Ergonomics, $32(2), 93-104,2003$

Yamada, F., Frontal midline theta rhythm and eyeblinking activity during a VDT task and a video game: useful tools for psychophysiology in ergonomics, Ergonomics, 41(5), 678-688, 1998.

Yen, C., A study of user's reading preference on vertically displayed dynamic Chinese information, IEEE, 6(11), 931-934, 2011.

\section{Author listings}

Songzhen Tong: tongsongzhen@163.com, tongsongzhen@gmail.com

Highest degree: BE, School of Traffic and Transportation, Beijing Jiaotong University, P.R. China

Position title: Master Student, Department of Industrial Engineering, Tsinghua University, P.R. China

Areas of interest: Cognitive Ergonomics, HCI

Pilsung Choe: pschoe@gmail.com,pchoe@tsinghua.edu.cn

Highest degree: PhD, Department of Industrial Engineering, Purdue University, USA

Position title: Associate Professor, Department of Industrial Engineering, Tsinghua University, P.R. China

Areas of interest: HCI, UX Design, User-Centered Design, Cognitive

Ergonomics, Information Processing and Decision Making

Pei Shi: shipei1988@sina.com

Highest degree: BE, Department of Precision Instruments and Mechanology, Tsinghua University, P.R. China

Position title: Master Student, Department of Industrial Engineering, Tsinghua University, P.R. China

Areas of interest: Visual search, HCI

Lin Yang: berting.young@gmail.com

Highest degree: BS, Faculty of Science, Minzu University of China, P.R. China

Position title: Master Student, Department of Industrial Engineering, Tsinghua University, P.R. China

Areas of interest: Driving Safety \& HM System Simulation, HCI

Date Received : 2013-03-04

Date Revised : 2013-04-03

Date Accepted : 2013-04-03 